\title{
A PRÁXIS ENUNCIATIVA NA PUBLICIDADE CONTEMPORÂNEA: A TENSÃO ENTRE PERMANÊNCIA E FUGACIDADE NOS RITUAIS DE COMPRA, USO E POSSE
}

\author{
The enunciative praxis in contemporary advertising: the tension between permanence \\ and fugacity in the ritual of purchase, use and possession
}

\section{La práxis enunciativa en la publicidad contemporánea: la tensión entre permanencia y fugacidad en los rituales de compra, uso y posesión}

\author{
Eneus Trindade ${ }^{1}$ \\ Pedro Hellin ${ }^{2}$ \\ Clotilde Perez ${ }^{3}$ \\ Paulo Lencastre ${ }^{4}$ \\ Leandro Batista ${ }^{5}$
}

\begin{abstract}
Resumo
Existem diferentes modos de presença do visível em nosso meio (LANDOWSKI, 2004), a publicidade se configura como uma manifestação privilegiada da sociedade contemporânea, baseada na sinestesia, na polifonia e na visualização dos conceitos de singularidade e exclusividade. Este feito está evidenciado pelo deslocamento do material do produto ou da organização, a favor da desmaterialização simbólica, erodindo o concreto
\end{abstract}

\footnotetext{
${ }^{1}$ Professor da Escola de Comunicações e Artes da Universidade de São Paulo, atuando na graduação em Publicidade e Propaganda e no PPGCOM/USP. Pós-Doutor em Antropologia Visual pela Universidade de Aberta -Portugal. Editor da Revista Signos do Consumo.

${ }^{2}$ Profesor Contratado Doctor. Imparte las asignaturas de Diseño de la Imagen Corporativa, y Sistemas y Procesos de la Publicidad y las Relaciones Públicas. Universidad de Murcia. Facultad de Comunicación y Documentación. Campus Universitario de Espinardo, s/n. 30100 Murcia. +34 868888 411. E-mail: phellin@um.es

${ }^{3}$ Professora Livre-Docente em Ciências da Comunicação do Departamento de Relações Públicas, Propaganda e Turismo da ECA/USP. Possui Pós-doutorado em Comunicação pela Universidade de Múrcia-Espanha. Doutora em Comunicação e Semiótica pela PUC-SP, Mestre em Administração pela PUC-SP. Docente do PPGCOM/ECA/USP na área de interfaces sociais da comunicação. Coordenadora dos Grupos de Estudos Semióticos em Comunicação, Cultura e Consumo CNPq/ECA/USP.

${ }^{4}$ Paulo Lencastre. Doutor e Mestre em Ciências Econômicas Aplicadas, Marketing, pela Universidade Católica de Lovaine, Bélgica. Professor da Universidade Católica Portuguesa, Portugal. Professor convidado no ISCTE em Portugal e na ECA - USP

${ }^{5}$ Leandro Leonardo Batista. Doutor em Comunicação Social pela University of North Carolina e Mestre em Propaganda pela University of North Carolina. Professor da ECA - USP junto a graduação em Publicidade e ao PPGCOM. Líder do GEPEC - Grupo de Estudos e Pesquisas dos Efeitos da Comunicação da USP.
} 
A práxis enunciativa na publicidade contemporânea: a tensão entre permanência e fugacidade nos rituais de compra, uso e posse

de Eneus Trindade, Pedro Hellin, Clotilde Perez, Paulo Lencastre e Leandro Batista 107

com a intenção de criar vínculos de sentido a partir da subjetividade para, com isso, estabelecer cumplicidade e identificação. A publicidade é uma presença efetiva, envolvente e intencionalmente acessível, criada como uma síntese da tensão entre a promessa de permanência (objetivo estratégico de produtos e marcas) e a fugacidade implacável característica do pragmatismo e o efêmero da oferta e a demanda contemporâneas. Neste contexto foram selecionados anúncios publicitários publicados nos últimos três anos nas principais revistas brasileiras, nas categorias de moda, tecnologia e alimentos, com mais de quinhentos exemplos. As categorias de produtos/marca foram selecionados a partir do critério de volume e frequência de aparição. Por meio de uma metodologia teóricoempírica, os anúncios foram analisados semioticamente e comparados com os mecanismos de transferência de sentido a partir das reflexões de McCracken (2003), o que permitiu a compreensão de como se realizam os processos de significação das marcas a partir dos rituais de compra, uso e posse evidenciados nos anúncios. Adicionalmente, analisamos os resultados sobre tendências obtidos na pesquisa do Observatório de Tendências do Instituto Ipsos (Brasil) e do Trend Report 2009/2010 do Instituto Trend Watching (Holanda). Há que se destacar que nas expressões plásticas e textuais publicitárias encontramos reflexos da sociedade em suas diferentes manifestações, seus valores e suas pautas de conduta, além de importantes índices para projetar previsões, o que reafirma a afirmação de que a publicidade é uma evidência privilegiada do mundo em que vivemos.

Palavras-chave: Publicidade; marcas; vínculos de sentido; tendências de consumo.

\begin{abstract}
There are different ways to he presence of visible in our environment (LANDOWSKI, 2004), the advertising is configured as a privileged manifestation of contemporay society, based on synesthesa, in polyphony and visualization of the concepts of uniqueness and exclusivity. This fact is evidenced by the displacement of the material of the productor organization, in favor of symbolic dematerialization, eroding the concrete with the intention os creating links from the sense of subjectivity, thereby establishing complicity and identification. The advertising and an effective presence, engaging and accesible intentionally created as a synthessis of the tension between the promise of permanence (strategic product and brand) and fugacity characteristic of ruthless pragmatism and ephemera of contemporary supply and demand. In this context we selected advertisements published in the last three years in the major brazilian magazine in the categories of
\end{abstract}


A práxis enunciativa na publicidade contemporânea: a tensão entre permanência e fugacidade nos rituais de compra, uso e posse

de Eneus Trindade, Pedro Hellin, Clotilde Perez, Paulo Lencastre e Leandro Batista 108

fashion, technology and food, with over five hundred examples. The categories of products/brands were selected from the criterion of volumen and frequency of appearance. Through a theoretical and empirical methodology, the ads were semiotically analysed and were compared with the mechanisms of transfer of meaning from the reflections of McCraken (2003) which allowed the understanding of how to perform the processes of meaning of the marks from rituals of purchase, use and possession evidenced in ads. Additionally, we analyze the results obtained on trends in the research of the Observatory of Trends in the Ipsos Institute (Brazil) and Trend Report 2009/2010 of Trend Watching Intitute (Netherlands). It should be noted that the plastic expressions and textual advertising find reflections of the society in its different manifestations, their values and patterns of behavior, and important indexes to design predictions, which confirms the claim that advertising is an insider's evidence of the world in which we live.

Keywords: advertising, brands, links of meaning, consumer trends.

\section{Resumen}

Existen diferentes modos de presencia de lo visible en nuestro medio (LANDOWSKI, 2004), la publicidad se configura como una manifestación privilegiada de la sociedad contemporánea, basada en la sinestesia, la polifonía y la visualización de los conceptos de singularidad y exclusividad. Este hecho está evidenciado por el desplazamiento de lo material en el producto o la organización, a favor de la desmaterialización simbólica, erosionando lo concreto con la intención de crear vínculos de sentido a partir de la subjetividad para, con eso, establecer complicidad e identificación. La publicidad es una presencia efectiva, envolvente e intencionalmente accesible, creada como una síntesis de la tensión entre la promesa de permanencia (objetivo estratégico de productos y marcas) y la fugacidad implacable característica del pragmatismo y lo efímero de la oferta y la demanda contemporáneas. En este contexto se han seleccionado anuncios publicitarios aparecidos en los últimos tres años en las principales revistas brasileñas, en las categorías de moda, tecnología y alimentos, hasta superar los quinientos ejemplos. Las categorías de productos/marca fueron seleccionadas bajo el criterio de volumen y frecuencia de aparición. Por medio de una metodología teórico-empírica, los anuncios han sido analizados semióticamente y comparados con los mecanismos de transferencia de sentido a partir de las reflexiones de McCracken (2003), lo que permitió la comprensión de cómo se realizan los procesos de significación de las marcas a partir de los rituales de compra, uso y 
A práxis enunciativa na publicidade contemporânea: a tensão entre permanência e fugacidade nos rituais de compra, uso e posse

de Eneus Trindade, Pedro Hellin, Clotilde Perez, Paulo Lencastre e Leandro Batista 109

posesión evidenciados en los anuncios. Adicionalmente, analizamos los resultados sobre tendencias obtenidos en la investigación del Observatório de Tendências del Instituto Ipsos (Brasil) y del Trend Report 2009/2010 del Instituto Trend Watching (Holanda). Es de destacar que en las expresiones plásticas y textuales publicitarias encontramos reflejos de la sociedad en sus diferentes manifestaciones, sus valores y sus pautas de conducta, además de importantes índices para proyectar previsiones, lo que reafirma la afirmación de que la publicidad es una evidencia privilegiada del mundo en que vivimos.

Palabras-clave: Publicidad; marcas; efectos; vínculos de sentido; tendencias de consumo

\section{INTRODUÇÃO}

Existem diferentes modos de presença do visível em nosso meio (LANDOWSKI, 2004), a publicidade se configura como uma manifestação privilegiada da sociedade contemporânea, baseada na sinestesia, na polifonia e na visualização dos conceitos de singularidade e exclusividade. Este efeito está evidenciado pelo deslocamento da materialidade do produto e da organização, a favor da desmaterialização simbólica, erodindo o concreto com a intenção de criar vínculos de sentido a partir da subjetividade e de representações espaciais e temporais para, com isso, estabelecer cumplicidade e identificação.

A publicidade é uma presença efetiva, envolvente e intencionalmente acessível, criada como uma síntese da tensão entre a promessa de permanência (objetivo estratégico de produtos e marcas) e a fugacidade implacável característica do pragmatismo e do efêmero da oferta e a demanda contemporâneas. Neste contexto selecionaram-se anúncios publicitários publicados nos últimos três anos nas principais revistas brasileiras, nas categorias de moda, tecnologia e alimentos, com mais de quinhentos exemplos catalogados.

As categorias de produtos/marca foram selecionadas a partir do critério de volume e frequência de aparição. Por meio de uma metodologia teórico-empírica, os anúncios foram analisados semioticamente e comparados com os mecanismos de transferência de sentido a partir das reflexões de McCracken (2003), o que permitiu a compreensão de como se realizam os processos de significação das marcas a partir dos rituais de compra, uso e posse evidenciados nos anúncios. Adicionalmente, analisamos os resultados sobre tendências obtidos na investigação Observatório de Tendências do Instituto Ipsos (Brasil) 
A práxis enunciativa na publicidade contemporânea: a tensão entre permanência e fugacidade nos rituais de compra, uso e posse

de Eneus Trindade, Pedro Hellin, Clotilde Perez, Paulo Lencastre e Leandro Batista 110

e do Trend Report 2009/2010 do Instituto Trend Watching (Holanda). Há que se destacar que nas expressões plásticas e textuais publicitárias encontramos reflexos da sociedade em suas diferentes manifestações, seus valores e suas pautas de conduta, além de importantes índices para projetar previsões, o que reafirma a certeza de que a publicidade é uma evidencia privilegiada do mundo em que vivemos.

Esclarecemos que, neste texto, em função de seus limites, abordaremos somente quatro do total de manifestações observadas, buscando generalizar sobre aspectos de uma nova retórica publicitária, pautada na práxis enunciativa das mensagens em suas representações subjetivas, espaciais e temporais, de acordo com os pressupostos da análise dos mecanismos formais da enunciação propostos por Benveniste (1966 e 1974).

\section{A PRÁXIS ENUNCIATIVA E A SEMIÓTICA PLURAL DA PUBLICIDADE: POSSIBILIDADES RETÓRICAS}

Nossa proposta segue distinta das importantes postulações inauguradas por Barthes (1969) e continuada em autores que se consagraram como proponentes dos modelos clássicos dos estudos da publicidade e áreas afins, como Péninou (1976), Eco (1997), Duran (1973), Joly (1986 e 1994), cuja discussão sobre tais modelos fundamentados na análise das denotações e conotações constituem-se como o primeiro grande contributo teórico-metodológico aos estudos das mensagens publicitárias em suas possibilidades retóricas, como bem descrevem Souza e Santarelli (2008).

No entanto, muito mais próximos de Floch (1990) e de suas considerações sobre a semiótica visual (1985), nossa proposta busca mostrar-se plural, enriquecendo-se com as recentes contribuições semióticas da vertente francesa, das considerações a partir do trabalho Charles Sanders Peirce (1977), bem como das aplicações e desenvolvimentos teóricos dessas abordagens por outros estudiosos ligados aos estudos da linguagem publicitária.

Ademais, este estudo também busca os sentidos da publicidade nas culturas de consumo, a partir dos vínculos de sentidos sugeridos pelas mensagens, pois a dinâmica enunciativa da construção de sentidos, que se faz nos processos de transferência de significados da fabricação do produto à construção dos vínculos de sentidos nos contextos de consumo, como apresenta McCraken (2003: 99-101), podem ser reveladores de práticas de consumo sugeridas que representam, segundo o antropólogo americano, as 
A práxis enunciativa na publicidade contemporânea: a tensão entre permanência e fugacidade nos rituais de compra, uso e posse

de Eneus Trindade, Pedro Hellin, Clotilde Perez, Paulo Lencastre e Leandro Batista 111

possibilidades de perfomance no consumo pelos rituais de compra, de posse e uso, que se estabelecem sobretudo pelo processo de mediação da publicização da marca como mediadora da produção para o consumo.

Este conjunto de relações permite lançar hipóteses sobre os efeitos das mensagens sobre o comportamento do consumidor, além de abrir perspectivas para os estudos comparados sobre as práticas de consumo sugeridas, como também definem tendências do consumo que se revelam por meio de tendências de linguagem. Dessa discussão surge a relevância epistemológica do presente trabalho.

Por meio da abordagem pela semiótica francesa, de inicio percebemos que a tensão entre fugacidade e permanência se dá em uma dinâmica tensiva que não se processa exclusivamente pela perfomance dos anúncios, mas sim, em uma perfomance do conjunto das mensagens da marca anunciada em seus vários suportes de publicização. Portanto, o percurso narrativo da marca é dinâmico e sua expressividade se articula em um parecer permanente, ainda que ao mesmo tempo se articula nos sentidos da experimentação do ser fugaz pela expressividade da publicização.

Nessa lógica, o percurso narrativo do consumo tenta, do ponto de vista do sujeito consumidor, a satisfação na oferta de uma experiência de consumo (uso que se concretiza pela compra e pelo sentido de posse), e a publicidade já é parte desta narrativa experiencial, enquanto programa narrativo auxiliar, em relação a esse programa narrativo principal da marca que é fazer-se como objeto de valor cognitivo da vida do consumidor, no sentido da experiência que marca o que se torna fugaz, e o produto, tanto em um caso como no outro, é o objeto de valor pragmático. Mas esse aspecto não se torna rentável para análise, visto que a superfície discursiva é o lugar privilegiado de investigação sobre esse processo de enunciação.

Para isso, torna-se necessário oferecer alguns parâmetros metodológicos para a análise retórica da publicidade de acordo com a perspectiva que aqui colocamos Trata-se de um protocolo que aborda no plano estético a tensão fugacidade e permanência, a partir de elementos visuais (traços eidéticos, tópicos e cromáticos) como postulou Floch (1985), para depois articulá-los com mecanismos de efeitos de sentido nos enunciados publicitários como sintetizamos em Trindade e Perez (2008) e Trindade (2009), a saber: efeitos representativos de sujeitos: personagens; spokeman; sujeito marca; sujeito produto; locutor/ narrador/ apresentador e o tempo e o espaço como sujeitos (TRINDADE e PEREZ, 2008: 12-15); efeitos representativos do tempo e do espaço: o tempo da novidade; 
A práxis enunciativa na publicidade contemporânea: a tensão entre permanência e fugacidade nos rituais de compra, uso e posse

de Eneus Trindade, Pedro Hellin, Clotilde Perez, Paulo Lencastre e Leandro Batista 112

o tempo da mensagem e do canal; o tempo economizado. Por fim, o tempo dos sujeitos. Já o espaço é visto pelos espaços mundializados/universais com imagens referentes ao espaço urbano das metrópoles comuns a vários contextos. Os espaços do produto/marca quando estes são os atores do espaço cênico na vida urbana; os espaços cotidianos; e o não-espaço, que diz respeito à questão da ilusão de ausência deste, proporcionada pelas novas tecnologias da comunicação/informação; os espaços fragmentados multiculturais que são amplamente trabalhados nas mensagens publicitárias do mundo contemporâneo, por meio de artifícios retóricos visuais e verbais, metonímicos, como as imagens de vários locais, regiões do mundo, pessoas de distintas etnias e localidades que, todavia remetem à representações distintas de subjetividades, estão associadas em seu todo, à ideia da ausência de fronteiras, nas quais a marca, o produto/serviço anunciado, é o elemento comum a esses contextos/espaços; e o corpo humano como espaço, espaço cênico, sujeito ocupante de espaços em que vive e transita (TRINDADE, 2009: 7-8).

Por fim, buscamos observar as representações de compra, posse e uso indicados nos signos das mensagens para a sugestão do vínculo construído e a análise sobre o efeito retórico identificado, a partir de interpretantes possíveis, como já discutido em Perez e Bairon (2009), que tratam das potencialidades do conceito de interpretante Peirciano, com vista a uma teoria da recepção.

Essas postulações permitirão a formulação do seguinte modelo de análise:

\begin{tabular}{|l|l|l|}
\hline $\begin{array}{l}\text { Dimensões } \\
\text { de análise }\end{array}$ & $\begin{array}{l}\text { Fugacidade } \\
\text { (intensidade, ruptura, } \\
\text { efervescência, tensão } \\
\text { contração, paixão) }\end{array}$ & $\begin{array}{l}\text { Permanência } \\
\text { (constância, consensualidade, } \\
\text { relaxamentos, distensão, apatia) }\end{array}$ \\
\hline $\begin{array}{l}\text { Valores da publicidade } \\
\text { ângulos, formas, continuidades e } \\
\text { descontinuidades). }\end{array}$ & \\
\hline $\begin{array}{l}\text { Dimensão cromática (contrastes, } \\
\text { degradées); }\end{array}$ & & \\
\hline $\begin{array}{l}\text { Dimensão tópica (inferior, superior, } \\
\text { centralizado, esquerdo, direito); }\end{array}$ & & \\
\hline Efeitos representativos de Sujeito & & \\
\hline Efeitos representativos de Espaço & & \\
\hline Efeitos representativos de tempo & & \\
\hline Representações do ritual de compra & & \\
\hline
\end{tabular}


A práxis enunciativa na publicidade contemporânea: a tensão entre permanência e fugacidade nos rituais de compra, uso e posse

de Eneus Trindade, Pedro Hellin, Clotilde Perez, Paulo Lencastre e Leandro Batista

\begin{tabular}{|l|l|l|}
\hline Representações do ritual de uso & \\
\hline Representações do ritual de posse & & \\
\hline \multicolumn{2}{|l|}{ Tipo de vínculo sugerido e análise sobre o efeito interpretante retórico identificado: } \\
\hline
\end{tabular}

Quadro 1- Protocolo de Análise retórica da práxis enunciativa da publicidade

\section{NOVA RETÓRICA DA PRÁXIS ENUNCIATIVA DA PUBLICIDADE}

A proposta de uma nova retórica da práxis enunciativa da publicidade, a partir dos autores apresentados e da capacidade analítica dos semioticistas, é um caminho possível para compreender os câmbios desta manifestação contemporânea por excelência que é a publicidade e lançar esforços no sentido de sistematizar uma metodologia de análise multidisciplinar. Cremos que somente com uma abordagem plural é possível apreender, ainda que parcialmente, a potencialidade dos complexos efeitos de sentido do mundo de hoje.

Como foco na aplicação do nosso protocolo de análise, elegemos quatro campanhas publicitárias dos segmentos de moda, tecnologia e alimentos. Em moda, selecionamos anúncios das marcas Diesel e Melissa; para tecnologia dos celulares, Nokia 5610; e, de alimentos, trabalhamos coma bebida láctea iogurte da marca Becel Pró-Activ. Iniciaremos nossa análise com Diesel.

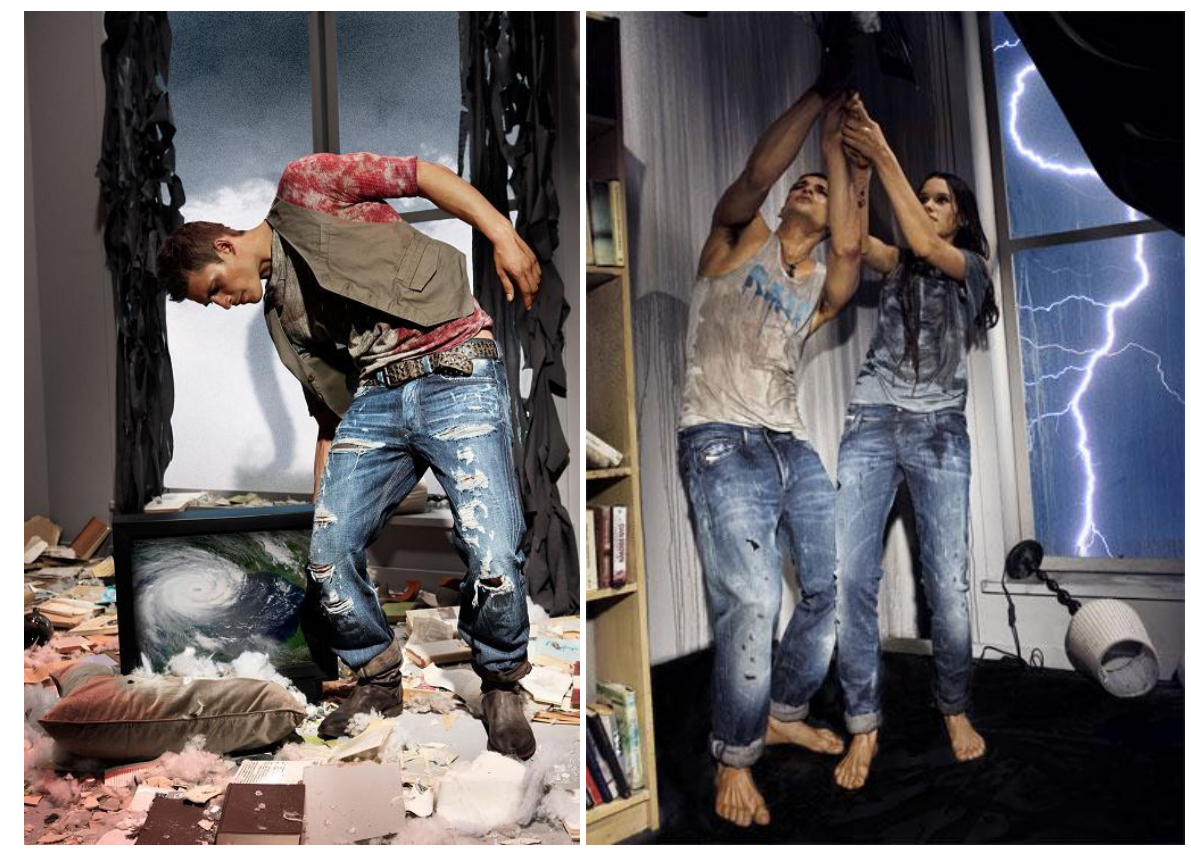

Fig. 1 - anúncios da campanha publicitária Diesel 2010 
A práxis enunciativa na publicidade contemporânea: a tensão entre permanência e fugacidade nos rituais de compra, uso e posse

de Eneus Trindade, Pedro Hellin, Clotilde Perez, Paulo Lencastre e Leandro Batista $\quad 114$

As condições climáticas extremas foram a inspiração conceitual da coleção que é tema da campanha publicitaria de Diesel 2010 (figura 1) para as roupas tipo jeans. A coleção se divide em três linhas centrais: rain, storm e destroyed.

As imagens dos anúncios representam uma sequência de transformações meteorológicas indiciadas por efeitos visuais eidéticos e sinestésicos no jeans: as manchas são índices da chuva, as linhas aludem aos raios das tempestades, e os rasgos à destruição que por fim se estabelece caoticamente. Apenas nessa primeira constatação se nota a busca por integrar a intencionalidade do sentido na materialidade do produto (calça jeans). As imagens fotográficas enfatizam jovens com jeans cuja atitude remete à independência, à individualidade, à irreverência, à vitalidade e à força: algo possível não apenas por meio de uma transformação externa no ambiente que inclui tempestades, ventos ou trovões, senão que por meio do poder que o jeans tem de proporcionar a dita mudança, em uma clara manifestação do empoderamento que a marca é capaz de gerar em sua subjetividade sígnica. Estas são marcas profundas da permanência em Diesel que cria adaptações no aspecto intenso da fugacidade em suas campanhas.

O tempo e o espaço estão em um jogo: o anúncio visual da mudança do tempo e seus reflexos caóticos no espaço. Constrói-se uma historicidade com marcas da passagem do tempo: céu escuro, raios e tempestade. Os espaços são internos, mas sempre com uma nesga de contato exterior (a comprovação do tempo), são espaços urbanos, com mobiliário contemporâneo.

Os efeitos interpretativos dos sujeitos estão borrados. Há aqui uma fusão entre a figura personagem com a personagem produto e o próprio tempo espaço como sujeitos, uma vez que os efeitos da destruição são "sofridos" pelas personagens e também pelas roupas jeans: manchas, raios e rasgaduras, tornando-os centrais na trama. A cenografia é compartilhada entre corpo e jeans e espaço-tempo em uma competição sem vencedores evidentes. O efeito interpretante retórico nesta campanha publicitária da Diesel é de total fugacidade, ancorada na intensidade, nas rupturas (climáticas e físicas do produto) e nas tensões evidentes do espaço.

Por meio da análise semiótica plural foi possível concluir que a marca Diesel realiza uma comunicação totalmente integrada ao produto e ao seu posicionamento global. A comunicação está integrada à estratégia de marca, utilizando elementos visuais com potencial para transmitir uma imagem condizente (recepção) com a identidade pretendida pela empresa (emissão). 
A práxis enunciativa na publicidade contemporânea: a tensão entre permanência e fugacidade nos rituais de compra, uso e posse

de Eneus Trindade, Pedro Hellin, Clotilde Perez, Paulo Lencastre e Leandro Batista 115

O foco da campanha Diesel está no ritual de uso para seguirmos os estudos de McCraken (2003). Os jeans, permeados pelos índices do tempo, tornando o corpo parte da cenografia triunfal do desfecho: a destruição. Não há evidências da compra, somente a sugestão dos usos dos personagens e posses que doam força por meio da marca Diesel, para viver a vida caótica contemporânea. Poderíamos classificar esta mensagem como de alta permanência nos sentidos profundos da marca e alta fugacidade na superfície do discurso manifestado em sua temática metafórica.

O segundo anúncio foco de nossa análise é da marca Melissa.

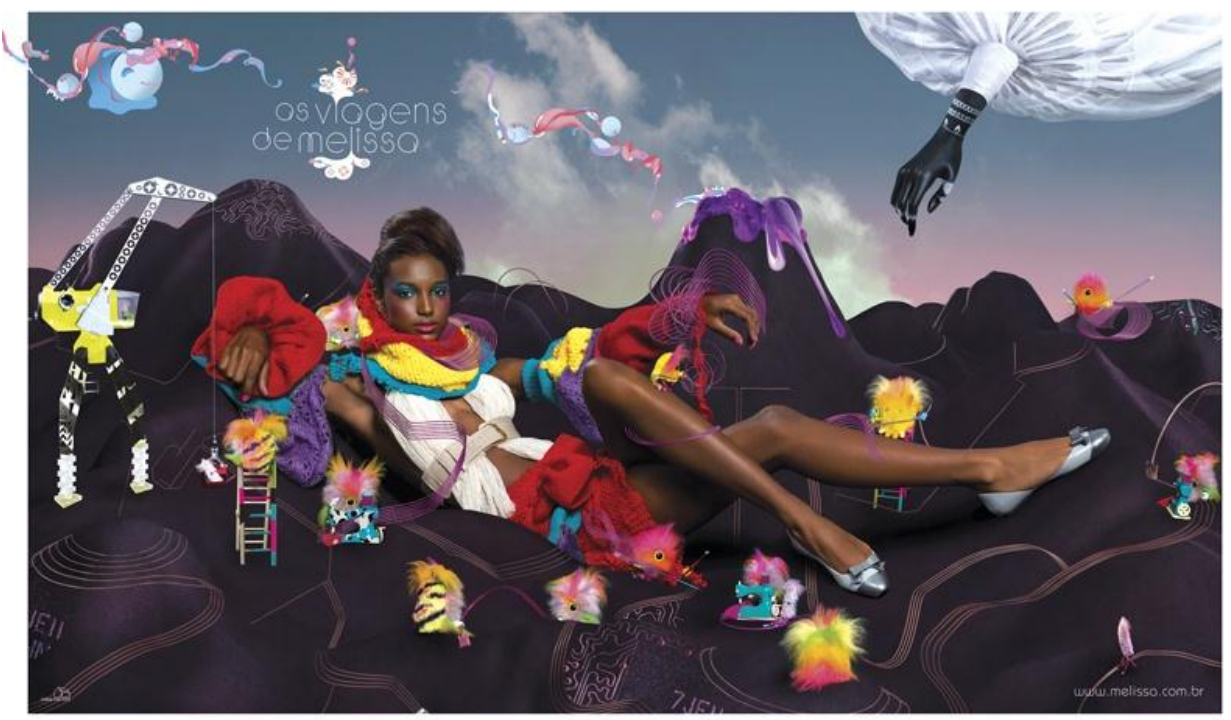

Fig. 2 - Anúncio da campanha "As viagens de Melissa"

A campanha publicitária "As viagens de Melissa" instaura a estética escapista da magia e do sonho conectando-se com a perspectiva surreal. Constituindo um universo psicodélico e multicolorido que materializa a fugacidade da proposta pela intensidade e contrastes dos elementos icônicos e cromáticos. Na dimensão eidética observamos os índices de movimento caracterizados pelas ondulações, recortes e linhas ascendentes que permeiam a cena, ademais das continuidades orgânicas do tecido-horizonte. A fugacidade está instaurada na intensidade visual, com cores fortes, brilho, dégradés e pela ludicidade geral da proposta, ao mesmo tempo que a permanência é construída por meio da suavidade das formas, dos tecidos (seda, cetim, pelúcia...), do conforto, do relaxamento e do recolhido semblante da modelo e, de modo indireto, proporcionado pelo uso do produto/marca Melissa. 
A práxis enunciativa na publicidade contemporânea: a tensão entre permanência e fugacidade nos rituais de compra, uso e posse

de Eneus Trindade, Pedro Hellin, Clotilde Perez, Paulo Lencastre e Leandro Batista 116

O anúncio é baseado nas representações do ritual de uso do produto que busca circunscrever as mulheres no universo da magia, da transformação e do sonho multicolorido e surreal, além da juventude.

Não há marcas seguras que permitam a identificação do espaço. Mas é um espaço próprio e onírico da publicidade de Melissa, como nos sonhos, pois o atordoamento visual é a intenção primeira. $\mathrm{O}$ céu poderia ser a marca exterior, mas as intervenções de imagens orgânicas e um braço e mão negros com manga branca que vêm das nuvens contrariam uma possível exterioridade real.

O efeito interpretante retórico instaurado pela campanha "As viagens de Melissa" é de permanência, caracterizada pela iconografia de relaxamento e constância. No melhor exemplo da publicidade como mediação entre os processos produtivos e o consumo. Ainda que também sejam detectados traços de fugacidade nos aspectos plásticos do mundo onírico e metafórico da publicidade de Melissa.

O terceiro anúncio é do segmento da tecnologia, com a marca de aparelhos celulares Nokia.

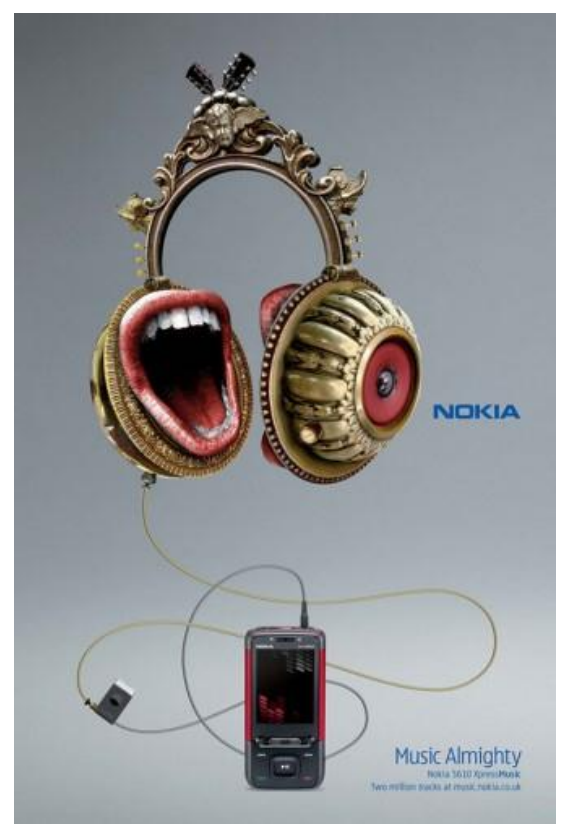

Fig. 3 - Anúnio da campanha Nokia 5610

A campanha para o celular Nokia 5610 apresenta uma grande exploração das dimensões eidéticas caracterizadas pela reiteração das linhas orgânicas que conectam o aparelho telefônico aos fones de ouvido hiperbólicos e em dupla mentonínima que substituem os fones/ouvidos por bocas abertas. O contraste cromático promovido pela 
A práxis enunciativa na publicidade contemporânea: a tensão entre permanência e fugacidade nos rituais de compra, uso e posse

de Eneus Trindade, Pedro Hellin, Clotilde Perez, Paulo Lencastre e Leandro Batista

mobilidade da cor cinza de fundo com a cor dourada e vermelha dos objetos funciona como perfeito atrator do olhar. Há uma clara polarização caracterizando a distribuição tópica em dois hemisférios: o inferior com o aparelho e o superior com os fones surreais.

O jogo temporal é marcante: o velho, posto em evidência pela materialidade metálica e pelo design barroco dos fones em um contraponto à tecnologia minimalista do aparelho celular. A representação hiperbólica e surreal dos fones remete à potência do som e subjetivamente a sua qualidade.

O anúncio expressa manifestações que se conectam com as representações de posse do produto uma vez que não coloca em cena o uso e tampouco a compra de maneira explicita. É a potência sígnica de quem tem o Nokia 5610, o acesso à magia e a excitação do exagero, da intensidade da imagem e subjetivamente da força do som.

O vínculo explorado é da potência da sensorialidade, com a busca do interpretante retórico da fugacidade caracterizado pela intensidade e exagero sinestésico do visualsonoro pela hipérbole e pela dupla metonímia da boca como fone para ouvidos. Poderíamos classificar o texto como uma negação da permanência, com traços retóricos que tendem à fugacidade, mas que ainda existe algo que se refere a permanência, mas não por sua afirmação e sim pela negação retórica do texto manifestado.

O último anúncio analisado é do iogurte Becel pro-activ. Vejamos.

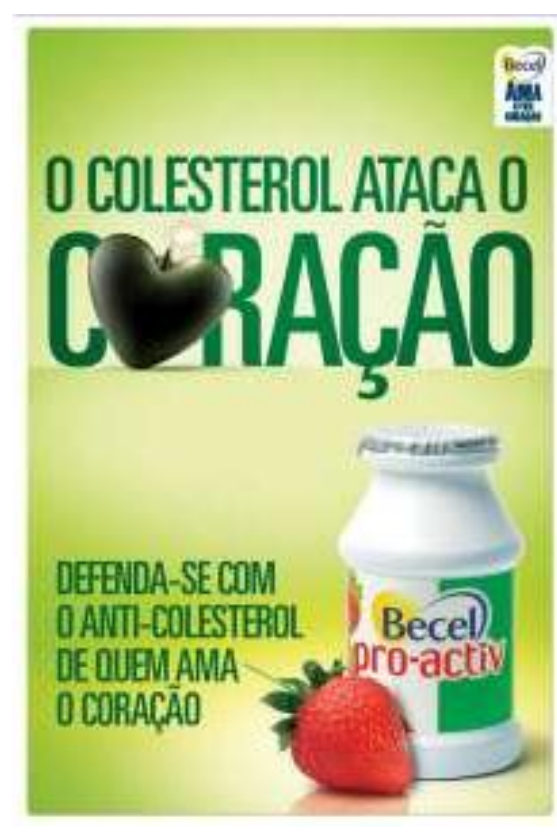


A práxis enunciativa na publicidade contemporânea: a tensão entre permanência e fugacidade nos rituais de compra, uso e posse

de Eneus Trindade, Pedro Hellin, Clotilde Perez, Paulo Lencastre e Leandro Batista 118

Na dimensão cromática destaca-se a mobilidade da cor de fundo verde construindo um suave contraste com a impressão gráfica do texto em verde escuro, com conexão direta à natureza e à saúde. Os elementos textuais são predominantes, o que caracteriza como uma comunicação de baixo contexto e mais racionalizante. Todavia, existe a iconografia da bomba preta em forma de coração que se conecta metaforicamente como efeito do colesterol, ou seja, o "ataque ao coração", ao mesmo tempo que surge a possibilidade de combate, anti-colesterol, de Becel pro-activ, “defenda-se!”. O “veneno" e o "antídoto”. Ou seja, uma construção metafórica de antítese e de hipérbole pela presença do produto como protagonista ao fundo.

Outro aspecto para ser considerado é que, apesar de o texto ocupar boa parte do anúncio, há uma exploração da dimensão afetiva, tanto por meio do texto em si "de quem ama o coração", como pelas imagens do coração e do morango (sabor do iogurte) que é uma fruta afetiva, carnuda, saborosa, com conexões de sensualidade e prazer.

Há vínculo evidente com a promoção da saúde por meio da alimentação, associada à portabilidade e a praticidade, condições essenciais da sociedade pós-moderna, fincada nos valores da rapidez, da simultaneidade, da conveniência e da efemeridade. Este texto não trabalha a afirmação plena sobre a permanência, todavia sejam percebidos signos de uma tradição retórica da publicidade, mas faz uma negação a fugacidade.

Das análises dos quatro anúncios selecionados, podemos fazer uma leitura dinâmica que facilita a sua interpretação recíproca. Partindo da relação de oposição inicial "fugacidade vs permanência", que pode ser caracterizada pelos anúncios Diesel vs Melissa, podemos perceber que a fugacidade pode ter permanências, assim como a permanência pode ter fugacidades. Como já havíamos dito.
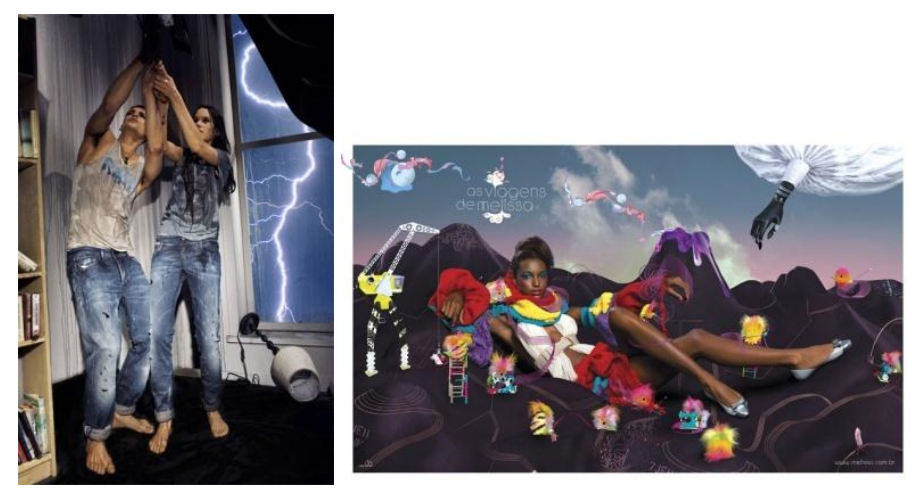
A práxis enunciativa na publicidade contemporânea: a tensão entre permanência e fugacidade nos rituais de compra, uso e posse

de Eneus Trindade, Pedro Hellin, Clotilde Perez, Paulo Lencastre e Leandro Batista

A categoria da "verticalidade vs. horizontalidade" remete claramente para a conotação extrema dos universos do fugaz e do permanente. Da mesma forma o instante do relâmpago $v s$ a estabilidade das nuvens, a queda desordenada do candelabro $v s$ a harmonia decorativa dos objetos expostos de Melissa, a roupa estragada $v s$ o traje principesco, a ação turbulenta do casal Diesel vs o estatismo contemplativo da princesa negra de Melissa.

Ainda que cada um dos extremos da polaridade seja reforçado pela presença mitigada dos conotadores de seu oposto. No caso Diesel, a estante que arruma os livros desarrumados é a âncora da estabilidade que reforça por contraste a turbulência da cena. No caso Melissa é a mão inesperada, exótica que, descendo do céu, acentua com seu movimento a atemporalidade do paraíso.

Esta análise torna-se muito mais ambígua quando nos deparamos com os anúncios Nokia e Becel. Ao deixarmos o universo explicitamente existencial da moda e adentrarmos no universo utilitário dos produtos de valorização mais prática, como diria Jean Marie Floch (1990), percebemos que o sentido está mais na negação do que na afirmação, quando forçamos a saída da pura praticidade para a utopia.
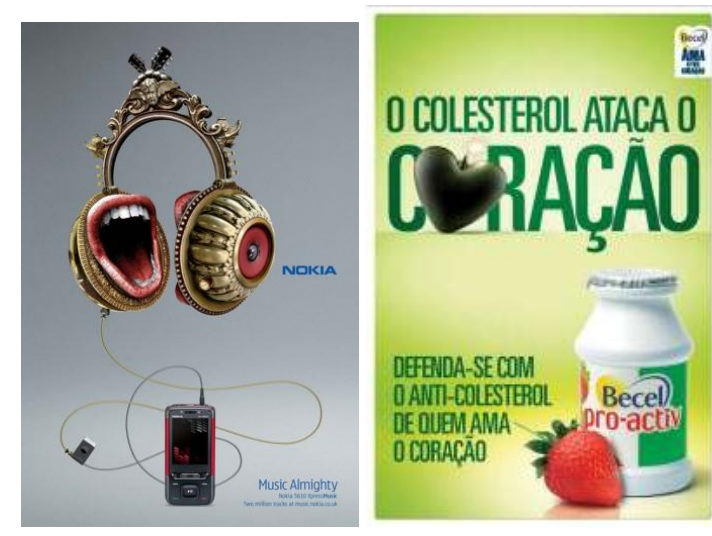

Tanto no caso Nokia, como no caso Becel, a presença dos contrários é explícita. À estabilidade clássica do celular, enquanto produto funcional, bem assentado na parte inferior da base, opõem-se a sua volatilidade barroca enquanto produto simbólico exibido na parte superior. Já a presença da saúde por meio do produto alimentar metaforizada pelo morango é o antídoto contra a ameaça do ataque vascular metaforizado por uma bomba (em forma de coração).

Em Nokia há uma promessa que se põe na negação da permanência, em Becel a promessa é a negação da fugacidade. Podemos com estes dois anúncios desdobrar no 
A práxis enunciativa na publicidade contemporânea: a tensão entre permanência e fugacidade nos rituais de compra, uso e posse

de Eneus Trindade, Pedro Hellin, Clotilde Perez, Paulo Lencastre e Leandro Batista 120

quadrado semiótico (ver Floch, 1993: 44-47) a categoria semântica inicialmente proposta: Fugacidade vs. Permanência.

Fugacidade Permanência

(Diesel) (Melissa)

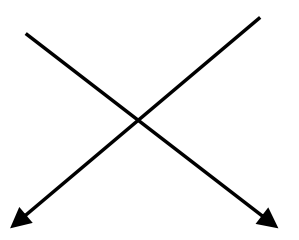

Não Permanência Não Fugacidade

(Nokia) (Becel)

A partir daqui poderíamos partir para análises muito mais complexas sobre a alteridade das marcas, em sua expressão e em seu conteúdo, no espaço de uma comunicação publicitária ou no tempo de suas vidas (Floch, 1993: 137-170; Lencastre, 2007: 199-207). No âmbito específico deste artigo desejamos somente subscrever como a fugacidade e a permanência, longe de serem realidades mutuamente exclusivas/excludentes, se conjugam na comunicação das marcas para tirá-las de seu universo referencial dos produtos de uso e elevá-las à condição de fenômenos míticos da vida contemporânea. Essas possibilidades também se refletem em novos processos cognitivos de compreensão do mundo, que neste caso é apresentado pela retórica da publicidade e que permite considerarmos algumas hipóteses.

\section{HIPÓTESES SOBRE OS EFEITOS DA PUBLICIDADE}

A implicação dos níveis de análise dos efeitos de sentido para os consumidores toma em consideração, como se viu anteriormente neste trabalho, os aspectos que receberam o maior peso na avaliação da comunicação publicitária. Na busca de apoio no "nível de conceitualização teórica" (TROPE e LIBERMAN, 2003; DHAR e KIM, 2007), um enfoque da psicologia social que examina como as pessoas percebem, compreendem e interpretam o mundo que as rodeia. Assim, quando temos as representações mentais das comunicações com um alto nível de "conceitualização", estas são percebidas como mais 
A práxis enunciativa na publicidade contemporânea: a tensão entre permanência e fugacidade nos rituais de compra, uso e posse

de Eneus Trindade, Pedro Hellin, Clotilde Perez, Paulo Lencastre e Leandro Batista

distantes e abstratas, enquanto que o baixo nível de "conceitualização" são aquelas que se percebem como mais próximas e concretas.

Portanto, podemos considerar o conteúdo da comunicação baseado em uma perspectiva a longo prazo, centrando-se no mais abstrato, que causa uma percepção relacionada com o mais completo e, portanto, mais difícil de alcançar, enquanto que, se o conteúdo se centrou em aspectos mais práticos, pode causar um sentido mais específico, vinculado aos detalhes mais singulares e, portanto, à permanência.

A expectativa é que o conteúdo da comunicação publicitária que se centra nos aspectos do produto busca um efeito mais concreto no curto prazo, enquanto que aqueles que se centram nos aspectos da marca são mais abstratos, buscando um efeito a longo prazo.

Por exemplo, na peça publicitária da Diesel, como se discutiu anteriormente, as imagens se destacam por aspectos abstratos (a independência, a individualidade, a irreverência etc.). Na combinação com os aspectos de tempo e espaço criando uma subjetividade cínica. Portanto, nos altos níveis de conceitualização, há evidência do uso ou da compra. Já em parte de "As viagens de Melissa", o anúncio se baseia em aspectos de uso, com um enfoque mais concreto, assim visando a permanência. A atenção se centra nos efeitos causados pela aquisição e pelo uso, assim vinculados ao curto prazo. Podemos observar estas características em outros momentos da análise, como se mostra a seguir.

Portanto, tendo em conta o contexto teórico atual, podemos esperar que, dentro da escala proposta no quadro 1, seja possível separar os efeitos de curto e de longo prazo a partir da aprovação e publicização do conteúdo da comunicação publicitária. As representações do ritual de compra, uso e posse deveriam aumentar a percepção da permanência (baixo nível de "conceitualização" ou interpretação), enquanto que os efeitos representantes do sujeito, espaço e tempo devam afetar a percepção de forma diferente em função de seu nível de abstração. Quando a pessoa se centra nas representações concretas se associa com a percepção de permanência, mas sim, estas representações são cada vez mais abstratas, portanto deve-se esperar uma sensação de fugacidade. Dimensões eidéticas de cor e tópicas devem determinar a ênfase nas representações.

\section{DA RETÓRICA ÀS PERSPECTIVAS DE TENDÊNCIAS DE CONSUMO: CONSIDERAÇÕES FINAIS}


A práxis enunciativa na publicidade contemporânea: a tensão entre permanência e fugacidade nos rituais de compra, uso e posse

de Eneus Trindade, Pedro Hellin, Clotilde Perez, Paulo Lencastre e Leandro Batista

Percebemos pelas discussões apresentadas que há muitas possibilidades de aplicação deste modelo teórico de análise fincado nos aspectos de uma práxis enunciativa e dos valores da fugacidade e permanência e como este caminho analítico pode ajudar a compreender tendências da retórica na publicidade, como também permitira construção de hipóteses sobre os efeitos de sentidos em termos de ações cognitivas pela interferência das mensagens publicitárias no cotidiano.

Ademais, esta proposta tenta compreender os rituais de consumo sugeridos nas mensagens que podem ajudar na percepção de tendências de consumo a partir das manifestações publicitárias. Tendências que se dão a perceber por manifestações visuais, textuais e sinestésicas que configuram uma possibilidade de investigação da cultura e do mercado.

\section{REFERÊNCIAS BIBLIOGRÁFICAS}

BARTHES, R. (1970). Rhétorique de l'image. Communications. Paris: Centre d'Études de Communications de masse. École Pratique des Hautes Études. n.15.

BENVENISTE, E. (1966) Problèmes de linguistique générale. Paris. Gallimard. (1974) Problèmes de linguistique générale II. Paris. Gallimard.

DHAR, R. e KIM, E. Y. (2007) Seeing the Forest or the Trees: Implications of Construal Level Theory for Consumer Choice. Journal of Consumer Psychology, 17(2), 96100.

DURAN, J. (1973) Retórica da imagem publicitária. In Metz, C. et al. Análise das imagens. Petrópolis: Ed. Vozes.

ECO, U. (1997) A estrutura ausente. 7ed. São Paulo: Ed. Perspectiva.

FLOCH, J-M. (1985) Petites mytologies de l'oeil et de l' espirit. Paris/Amsterdan: HadèsBenjamin.

(1990) Sémiotique, marketing et communication. Sous les signes, les stratégies.

Paris: Presses Universitaires de France. Traducción em castellano (1993) Sémiotica, marketing y comunicación. Bajo los signos, las estrategias. Barcelona: Paídos Comunicación.

JOLY, M. (1986) Introdução a uma análise da imagem. 2ed. Campinas: Papirus. (1994) L'image et les signes aproche semiologique de l'image fixe. NATHAN. Université. Nathan. pp.139-176. 
A práxis enunciativa na publicidade contemporânea: a tensão entre permanência e fugacidade nos rituais de compra, uso e posse

de Eneus Trindade, Pedro Hellin, Clotilde Perez, Paulo Lencastre e Leandro Batista

LANDOWSKI, E (2004). Flagrantes delitos e retratos. In Galáxia, n. 8, São Paulo: PUC-

SP, pp. 31-70.

LENCASTRE, P. (2007) Semiótica da Marca, in Lencastre P. (Ed.) O Livro da Marca. Lisboa: Dom Quixote, pp. 169-211.

McCRACKEN, G. (2003) Cultura e consumo. Novas abordagens ao caráter simbólico dos bens e das atividades de consumo. Rio de Janeiro. Ed. Mauad. Trad. Fernanda Eugênio. Coleção Cultura e Consumo coordenada por Everardo Rocha.

OBSERVATÓRIO DE TENDÊNCIAS IPSOS, edições 2004, 2005, 2006 e 2008.

PEIRCE, C.S. (1977). Semiótica. São Paulo: Perspectiva.

PÉNINOU, G. (1976) Semiótica de la publcidad. Barcelona. Ed. Gustavo Gili.

PEREZ, C. (2004) Os signos da marca. Expressividade e sensorialidade. São Paulo. Thomson Learning.

. \& BAIRON, S. (2009) Imagem de marca: a recepção sígnica a partir do interpretante peirceano. Animus. Revista Interamericana de Comunicação Midiática. Santa Maria: Programa de Pós-Graduação em Comunicação da Universidade Federal de Santa Maria. v.15. n.1. p.1-15.

SOUZA, S. M. R e SANTARELLI, C. P. G. (2008) Contribuições para uma história da análise da imagem no anúncio publicitário. Revista Brasileira de Ciências da Comunicação. São Paulo: INTERCOM. v.31. n.1. p.133-156.

TRENDWATCHING 2009/2010. Trend Report in www.trendwatching.com

TRINDADE, E. (2009). Da etnografia à produção de sentido da recepção publicitária e das práticas de consumo na vida social. Animus. Revista Interamericana de Comunicação Midiática. Santa Maria: Programa de Pós-Graduação em Comunicação da Universidade Federal de Santa Maria. V. 15. n.1. p.1-14.

\& PEREZ, C. (2008). O discurso publicitário e os sujeitos plurais. In RIBEIRO,

J. S; HELLIN, P; MEISTER, I (orgs.) Seminário Internacional-Imagens da cultura. Cultura das Imagens ANAIS. Porto: Universidade Aberta de Portugal. 2008. $1^{\circ}$ CD/Rom.

TROPE, Y. e LIBERMAN, N. (2003). Temporal Construal. Psychological Review. V. 110, N. 3, p. 403-421.

Artigo recebido:

Artigo aprovado: 